\title{
Time Travel, Audiovisual Narratives and TV Fiction: The Bootstrap Paradox in BBC's Doctor Who
}

\author{
Viajes en el tiempo, narrativa audiovisual y ficción televisiva: la paradoja circular en la \\ serie de la BBC Doctor Who \\ Juan Manuel Ruiz Prieto \\ Universidad Rey Juan Carlos, España
}

\begin{abstract}
The purpose of this work is to explore the narrative mechanisms that operate in audiovisual stories about time travel, and more specifically in those that address the so-called onthological paradox (also known as bootstrap paradox or causal loop), taking as a case study the British BBC TV series Doctor Who (19632020), and especially its modern era, which began in 2005.

Onthological paradoxes (those where an infinite cause-effect loop is created, and therefore it is impossible to establish a point of origin of certain events) break, by their own conception, the classical structure of the story by denying the classical notion of 'first plot point'. Thus, many of these narratives are forced to seek alternative formulas of temporal architecture based on simultaneity, order distortion or circularity. All these solutions can be traced in many chapters of Doctor Who, particularly in those that fall under the creative direction of Steven Moffat, who in his period as screenwriter (2005-2010) and showrunner (2010-2017) used the concept of 'time 'as the main driving force behind his narratives.
\end{abstract}

Keywords: Time Travel, Onthological Paradox, Doctor Who, Narrative Temporality, Television

\section{Introducción}

La narrativa audiovisual clásica, heredera de la literatura, se construye sobre la noción de causalidad. La doble articulación del relato cinematográfico implica la superposición de la dimensión temporal y la causal: esto es, la imagen cinematográfica incorpora en sí el tiempo, pero para la existencia del relato es condición necesaria que al transcurso de dicho tiempo se sume una serie de acciones que se relacionan entre sí de manera lógica, de modo que una acción es consecuencia de la anterior (Canet y Prósper 2009, 19). Se trata de una idea presente ya en la Poética de Aristóteles, quien sostenía que las acciones:

Deben nacer de la estructura misma de la fábula, de suerte que resulten de los hechos anteriores o por necesidad o verosímilmente. Es muy distinto, en efecto, que unas cosas sucedan a causa de otras o que sucedan después de ellas. (Aristóteles 2010, 163)

De esta arquitectura basada en la lógica estructural (Sánchez-Escalonilla 2001, 52) se derivan los modelos considerados canónicos en el cine de ficción, y defendidos por los teóricos del guion hollywoodiense: de ellos, el predominante es el que propugna una estructura en tres actos, con detonante, puntos de giro, clímax y resolución (Sánchez-Escalonilla 2001, 118). Esto implica una sucesión en el orden del relato que, si bien puede descomponerse y reordenarse en la narración (mediante los recursos evidentes: analepsis y prolepsis), mantiene la lógica interna del film en todo momento. Todo ello influye de manera determinante en la experiencia espectatorial, en tanto que el receptor recurre a las nociones de causa y efecto para descifrar el significado de lo que está viendo:

Por lo general, el espectador intenta activamente conectar los hechos mediante la causa y el efecto. Dado un incidente, tendemos a establecer hipótesis sobre qué puede haberlo causado o sobre lo que, a su vez, podría causar. Es decir, buscamos motivaciones causales. (Bordwell y Thompson 1995, 69)

Sin embargo, las narraciones que incluyen en sus mecánicas los viajes en el tiempo albergan la posibilidad de introducir variables de muy diversa índole en sus estructuras narrativas, al permitir permutaciones nuevas entre el tiempo diegético, el tiempo extradiegético, el orden de la acción frente al del relato y el punto de vista. Si bien la ficción tradicional no tiene por qué ser lineal, al permitir la mencionada organización a base de flashbacks y flashforwards, desordenando en la narración el orden natural de la diégesis (Bordwell y Thompson 1995, 70), sí es unidireccional, en tanto que este último, independientemente de cómo se muestre al espectador, sigue el discurrir natural del flujo temporal. Es decir, nace del pasado para extenderse hacia el futuro. La ficción de viajes en el tiempo, sin embargo, rompe esta obligatoriedad, puesto que la experiencia solo está obligada a ser unidireccional si el relato se ancla férreamente al punto de vista de un único personaje, o bien de un grupo de ellos que transite la misma ruta temporal.

\section{Causalidad, linealidad y direccionalidad}

En ese sentido, podemos sostener que, a las variables tradicionales-orden de la historia y orden del discurso (Canet y Prósper 2009, 270)-, para abordar el análisis estructural del relato de viajes en el tiempo sería necesario añadir otra, que podría denominarse direccionalidad de la historia. Esta nueva variable se definiría por el orden natural del flujo del tiempo (pasado-presente-futuro). Así, un film tradicional puede mostrarse de manera no lineal (si el orden del discurso no coincide con el orden de la historia) pero sí unidireccional 'natural' (el orden de la historia sigue un vector desde el pasado hacia el futuro), mientras que un film de viajes en el tiempo puede ser, 
independientemente de su linealidad, unidireccional (todos los personajes experimentan los sucesos en el mismo orden) o multidireccional (distintos personajes experimentan los mismos sucesos en orden distinto).

Ahora bien, esta propuesta de análisis plantea un problema añadido en relación con el viaje en el tiempo: ¿qué temporalidad se adopta como referente: la del discurrir histórico o la del viajero del tiempo?

Todo análisis temporal resultaría incompleto si no se aborda en relación con la cuestión de la enunciación y lo que Genette denomina el modo del relato (Aumont y Marie 1990, 150-151), que a su vez surge de la identificación del enunciador:

\footnotetext{
Para la pregunta ‘¿Quién ve?' existen tres respuestas posibles:

1. Un narrador omnisciente que dice más de lo que saben los personajes;

2. Un narrador que solo dice aquello que ve un determinado personaje (relato 'desde el punto de vista', 'visión con');

3. Un narrador que dice menos de lo que sabe el personaje (...).

Los relatos del tipo 1 son no focalizados (...)

Los relatos del tipo 2 son de focalización interna, fija (jamás se abandona el punto de vista de un personaje [...]), variable (se pasa de un personaje al otro) o múltiple (se cuentan los mismos acontecimientos muchas veces, según los puntos de vista de los distintos personajes).

Los relatos del tipo 3 son de focalización externa (Francis Vanoye, citado en Aumont y Marie 1990, 151).
}

Por tanto, para analizar la cuestión de la direccionalidad es necesario identificar primero la focalización, lo que a su vez permitirá establecer el tiempo de referencia o tiempo 0 del relato. Si la focalización es interna fija, es decir, si el relato se narra desde el punto de vista de un único personaje, será este quien determine el tiempo de referencia: la narración avanzará con él, y el espectador lo acompañará. Si el personaje que presta su punto de vista resulta ser un viajero temporal, el espectador experimentará los mismos saltos que él, percibiendo su tiempo y dirección como constantes, y el tiempo de la historia como discontinuo y desordenado. Por el contrario, si el punto de vista se adhiere a un personaje distinto al viajero temporal (es decir, si el relato sigue a una persona que no viaja en el tiempo), el espectador percibirá el tiempo de la historia como constante, y será la figura del viajero temporal la que se presente como discontinua y desordenada.

Para solventar las dificultades (en buena medida terminológicas) que plantea el análisis de estas temporalidades separadas, el filósofo David Lewis propone la distinción entre tiempo externo (el discurrir natural de la Historia) y tiempo personal del viajero ("a grandes rasgos, el que mide su reloj de pulsera", Lewis 1976, 146).

\section{Estudio de caso: Doctor Who}

Doctor Who (1963-1989, 2005-actualidad) ${ }^{1}$ es una serie de televisión británica producida por la cadena pública BBC. Su protagonista es un alienígena de apariencia humana, conocido simplemente como 'el Doctor', que se desplaza por el tiempo y el espacio a bordo de la TARDIS, una máquina del tiempo con forma de cabina telefónica.

Si bien fue concebida inicialmente como una serie con valor educativo, donde los viajes en el tiempo eran el pretexto para colocar a los personajes en momentos clave de la historia de la humanidad (los seriales ${ }^{2}$ An Unearthly Child, Marco Polo, The Aztecs o The Romans son un buen ejemplo de ello), los guionistas rápidamente comenzaron a aprovechar las posibilidades de su premisa narrando también historias ubicadas en el presente y en el futuro. El Doctor es un individuo que viaja por el tiempo libre y lúdicamente, por el mero placer de viajar, y va encontrando problemas en su camino y deshaciendo entuertos como si se tratase de un Quijote intergaláctico.

La serie fue cancelada en 1989 tras 26 temporadas supervisadas por diferentes showrunners. En 2005 la BBC daría luz verde a una continuación, bajo la dirección creativa de Russell T. Davies (responsable de otros productos televisivos como Queer as Folk, Casanova o, más recientemente, Years and Years e It's a Sin). En 2010, Steven Moffat ocupó el lugar de Davies, y en 2018 Moffat fue reemplazado por Chris Chibnall, quien actualmente continúa desempeñando la labor de showrunner. Desde 2005, la serie se compone de capítulos individuales de una duración cercana a los 45 minutos, estructurados en temporadas de 12-13 episodios cada una, a los que se suman varios especiales unitarios.

Por su longevidad, Doctor Who ha explorado inevitablemente muy distintas permutaciones entre estas variables. De especial interés resulta, dentro de esta larga trayectoria, la obra de Steven Moffat, el autor que, en su período como guionista ocasional (2005-2010) y director creativo (2010-2017) de la serie, ha explorado con mayor profundidad las posibilidades narrativas del viaje temporal.

\section{Tiempo lineal, tiempo arborescente y tiempo rizomático}

En su artículo Deleuze and the Doctor: Rhizomorphic Time Travel in Doctor Who, Sam Steele recoge la categorización de Matt Hills $(2010,92)$ de los episodios de Doctor Who en dos tipos de relatos. Partiendo de la afirmación de Barney Warf de que "las concepciones occidentales de la Historia son las únicas que se apoyan en una concepción lineal y no cíclica del tiempo" (Warf 2002, 19), Hills divide los capítulos de Doctor Who en dos tipos: por un lado, aquellos que siguen una lógica lineal; por otro, los que muestran el viaje temporal como "una ruta arborescente, donde el 
amanecer de los tiempos sería la raíz inicial, y el fin del universo la punta de la última rama" (Steele 2018, 49). Cualquier viaje al pasado, por tanto, seguiría una lógica lineal, al desandar el camino único de la Historia; los viajes al futuro, por el contrario, pueden mostrarse como lineales (cuando se presenta dicho futuro como un elemento prefijado e inmutable), pero también como arborescentes (cuando el futuro que se muestra representa únicamente una posibilidad entre muchas otras, que constituyen las diferentes ramas). A esta clasificación, Steele propone añadir un tercer tipo:

Contrariamente a la observación crítica realizada por Hills y Warf, sostengo que hay algunos elementos en el formato de ciencia ficción de Doctor Who que pueden considerarse rizomórficos en lugar de arborescentes (Steele 2018, 49).

Para ello, se apoya en la noción de rizoma postulada por Gilles Deleuze y Félix Guattari, quienes abogan por un modelo (de pensamiento, pero también de construcción narrativa) que esquive toda noción de conectividad lineal (por más que esas líneas se ramifiquen en una estructura en árbol). Sin embargo, es necesario detenerse a considerar los principios del rizoma, tal como los describen Deleuze y Guattari:

Principios de conexión y de heterogeneidad: cualquier punto del rizoma puede ser conectado con cualquier otro, y debe serlo. (...) Principio de multiplicidad: sólo cuando lo múltiple es tratado efectivamente como sustantivo, multiplicidad, deja de tener relación con lo Uno como sujeto o como objeto, como realidad natural o espiritual, como imagen y mundo. Las multiplicidades son rizomáticas y denuncian las pseudomultiplicidades arborescentes. (...) Principio de ruptura asignificante: frente a los cortes excesivamente significantes que separan las estructuras o atraviesan una. Un rizoma puede ser roto, interrumpido en cualquier parte, pero siempre recomienza según ésta o aquella de sus líneas, y según otras. (...) Principio de cartografía y de calcomanía: un rizoma no responde a ningún modelo estructural o generativo. Es ajeno a toda idea de eje genético, como también de estructura profunda (Deleuze y Guattari 2004, 13).

Es decir, que la naturaleza del rizoma rechaza la linealidad, la unicidad y la estructura, decantándose en su lugar por una suerte de forma bulbosa y cambiante, con infinitas posibilidades de conexión interna o externa.

Así pues, en efecto, Doctor Who presenta episodios donde el tiempo se presenta bajo una naturaleza lineal (como ya se ha expuesto con anterioridad, todos los relatos de viaje al pasado), arborescente (The End of The World) o rizomática (Father's Day o The Fires of Pompeii, siguiendo los ejemplos propuestos por Steele). Sin embargo, hay una manifestación del viaje temporal que desafía no solo las dos categorías propuestas por Hills, sino también la tercera sugerida por Steele. Se trata de las paradojas circulares. El presente estudio se centra en los episodios Blink (Doctor Who: Blink, 2007), Under the Lake (Doctor Who: Under The Lake, 2015) y Before the
Flood (Doctor Who: Before the Flood, 2015), cuyo mecanismo narrativo descansa sobre dicha mecánica.

\section{La paradoja circular}

Una paradoja circular es un bucle causal, es decir, "una cadena causal cerrada en la que algunos de los vínculos causales son de dirección normal y otros de dirección invertida" (Lewis 1976, 148). En la paradoja circular un evento A produce un efecto B, pero a su vez, por medio del viaje temporal al pasado, dicho efecto $B$ es el causante del evento $A$ (estructura $A \rightarrow B \rightarrow A$...).

En uno de los capítulos de Doctor Who analizados en este estudio, el Doctor explica verbalmente este tipo de paradoja:

Un hombre tiene una máquina del tiempo (...). También tiene pasión por la obra de Ludwig van Beethoven. Y un día piensa '¿de qué sirve tener una máquina del tiempo si no la usas para conocer a tus héroes?' Así que viaja a la Alemania del siglo XVIII, pero no encuentra a Beethoven. Nadie ha oído hablar de él. Ni siquiera su familia sabe de quién habla el viajero del tiempo. Beethoven, literalmente, no existe (...). Esto se llama paradoja ontológica. Buscadlo en Google. El viajero temporal entra en pánico. No pude soportar la idea de un mundo sin la música de Beethoven. Por suerte, ha traído todas sus partituras de Beethoven para que Ludwig se las firme. Así que copia todos los conciertos y las sinfonías, y las publica. Se convierte en Beethoven. Y la historia continúa sin despeinarse. Pero mi pregunta es... ¿quién juntó esas notas y frases? ¿Quién compuso realmente la $5^{\text {a }}$ Sinfonía de Beethoven? (Doctor Who: Before the Flood, 2015)

En el ejemplo dado, se puede comprobar la imposibilidad de establecer el punto de origen de la cadena de acontecimientos, como si se tratase de la vieja cuestión de 'el huevo o la gallina'. La introducción de la paradoja circular desafía la organización lineal de los elementos del relato (A es la causa de B, B es la causa de $\mathrm{C}$, etc.), pero tampoco se ajusta al esquema arborescente de Warf, puesto que las ramificaciones son imposibles ( $A$ conduce a $B$, y a su vez $B$ acaba regresando inevitablemente a $A$; no puede derivar en una opción $\mathrm{C} \circ \mathrm{D})$. $\mathrm{Y}$, en última instancia, tampoco puede considerarse una naturaleza rizomática, porque no cumple ninguno de sus principios, tal y como estos se han reproducido más arriba: la paradoja circular no permite la multiplicidad y la heterogeneidad, la ruptura asignificante o la libre conexión de unos puntos con otros; del mismo modo, no puede ser ajena a "toda idea de eje genético, como también de estructura profunda" (Deleuze y Guattari 2004, 13), puesto que la causalidad (y por tanto la estructura) es una parte fundamental de su funcionamiento. Teniendo todo esto en cuenta, puede decirse que la narración en forma de paradoja circular se escapa de los esquemas propuestos para situarse en un punto intermedio entre la narrativa tradicional (jerarquía causa-efecto) y un modelo de narración rizomática (sin dicha jerarquía). 
El reto para el narrador estará, pues, en escoger el punto de inicio de su relato: un relato que, siendo esencialmente el mismo, se mostrará de forma diferente al espectador en función de esta elección fundamental. Por supuesto, el hecho de presentar un relato de manera 'desordenada' no es novedoso. La diferencia en el caso de la paradoja circular estriba en que es el propio relato el que no tiene un punto de origen claro. Esto es: independientemente de la voluntad del narrador, es imposible situar una causa primera. Por acudir a otro ejemplo de la cultura popular, Pulp Fiction (Pulp Fiction, 1994) despliega su discurso en un orden distinto al de los hechos, mientras que en Blink (Doctor Who 2005, temporada 3, episodio 10) sencillamente no existe un orden único de los sucesos de su trama.

\section{Blink}

El punto de vista en Doctor Who oscila casi invariablemente entre el propio protagonista (el Doctor) y sus diversos acompañantes humanos, que toman parte en sus aventuras. Sin embargo, el caso de Blink resulta una interesante anomalía en la serie en lo tocante a su focalización narrativa, puesto que, aunque se trata principalente de un relato de focalización interna fija, esta no corresponde ni al Doctor (David Tennant) ni a su acompañante Martha (Freema Agyeman), sino a un personaje externo, Sally Sparrow (Carey Mulligan, en su única aparición en la serie), que no participa en el viaje temporal y solo es testigo de sus consecuencias.

La trama del capítulo es, a grandes rasgos, la siguiente: la joven Sally Sparrow recibe mensajes misteriosos de alguien del pasado que parece conocer su futuro. Al investigar, Sparrow descubre que esos mensajes proceden del Doctor, que se ha quedado varado en el año 1969 por culpa de unos seres conocidos como ángeles llorosos. Estas criaturas, de aspecto parecido a estatuas de piedra, tienen el poder de mandar a la gente al pasado solo con tocarlos ${ }^{3}$; al Doctor lo han desplazado súbitamente a los años sesenta desde el presente (2007). Su máquina del tiempo, la TARDIS, ha permanecido en el siglo $\mathrm{XXI}$, por lo que él no puede regresar. Al darle a la joven información sobre lo que va a ocurrir, esta consigue escapar de los ángeles, recuperar la TARDIS y activarla para enviarla a 1969, para que así el Doctor pueda volver a desplazarse con libertad por el tiempo.

Hasta aquí todo parecería (más o menos) una trama normal dentro de la serie. Sin embargo, tras el clímax queda en el aire un interrogante que se resuelve en los últimos minutos: ¿cómo podía el Doctor saber lo que iba a ocurrirle a Sally en su futuro inmediato? La escena final del episodio muestra cómo Sally, tras toda su peripecia, se encuentra con el Doctor. En una breve conversación queda claro que, en este punto de la vida del Doctor (en su tiempo personal, por seguir la clasificación de Lewis), este aún no ha vivido su encuentro con los ángeles llorosos ni su desplazamiento a 1969; tampoco conoce a Sally ni sabe nada de ella. Es entonces cuando la joven le entrega todas sus anotaciones sobre la aventura que ha vivido; a partir de ahora, él tendrá la información necesaria para cuando su versión futura se encuentre con la Sally del pasado.

Lo que aquí sucede es que la información no puede tener un punto de origen. El elemento más notable es una conversación en la que el Doctor, en 1969, deja grabadas en un vídeo sus respuestas a preguntas que Sally formulará, al ver dicho vídeo, en 2007. ¿Cómo puede él saber las preguntas de Sally? Sencillamente, gracias a transcripción que le entregó la Sally futura. Pero a su vez, Sally pudo realizar las preguntas porque encontró el vídeo del Doctor con las respuestas. En una conversación normal, las respuestas son consecuencia de las preguntas, mientras que en esta paradoja circular, las preguntas son a su vez consecuencia de las respuestas ${ }^{4}$.

En aras de la claridad, el esquema de la acción, desde el punto de vista del Doctor, es el siguiente:

1. En 2007, El Doctor encuentra a Sally, quien le hace entrega de las anotaciones, incluida una transcripción de una conversación entre ambos (que para él aún no ha tenido lugar).

2. En un momento indeterminado, el Doctor se ve transportado a 1969 por los ángeles llorosos mientras su vehículo temporal (la TARDIS) queda en el presente. Gracias a las anotaciones de Sally, el Doctor registra en vídeo sus respuestas a la conversación.

3. En 2007 (pero en un momento de la línea temporal anterior al punto 1) Sally se encuentra con los ángeles llorosos y con el vídeo del Doctor. Ella interactúa con el vídeo. Su amigo Larry presencia la 'conversación' de Sally con la grabación y anota el diálogo resultante.

\section{Sally consigue devolver la TARDIS a 1969 para que} el Doctor pueda escapar de ese año.

Sin embargo, desde el punto de vista de Sally, el orden es notablemente distinto: 3-4-1. Estrictamente hablando, el punto $n^{\circ} 2$ (el Doctor es transportado a 1969) no forma parte del relato de Sally, pero su lugar en la cadena de acontecimientos lo sitúa invariablemente entre el 1 (el Doctor encuentra a Sally) y el 3 (Sally se encuentra con los ángeles y con el vídeo del Doctor). Porque, a diferencia de la estructura rizomática, donde "cualquier punto del rizoma puede ser conectado con cualquier otro, y debe serlo" (Deleuze y Guattari 2004, 13), en la paradoja circular sí hay un orden establecido, igual que en la estructura lineal; a diferencia de esta última, lo que no hay es un principio obligatorio. En la cadena de acontecimientos arriba expuesta, al 1 siempre le sucederá el 2; al 2 siempre le sucederá el 3 , y al 3 siempre le sucederá el 4 , pero la particularidad 
aquí consiste en que al 4 no le sucederá el 5 , sino el 1. Un bucle cerrado que, por su propia naturaleza, no se puede romper: necesita de todos y cada uno de sus sucesos para mantenerse estable.

Por tanto, en la línea de lo explicado más arriba, la primera decisión narrativa que conforma y define al episodio es la siguiente: ¿En qué punto se va a introducir al espectador en el bucle? Un episodio tradicional de Doctor Who habría comenzado con el Doctor quedándose atrapado en el pasado: la focalización interna fija habitual de la serie implicaría que el espectador observa los hechos en el orden en que los experimenta el viajero temporal, en este caso el Doctor. Sin embargo, Steven Moffat esquiva en esta ocasión el punto de vista del Doctor para proponer una focalización interna fija distinta, acompañando en este caso a un personaje anónimo, Sally, y disponiendo por tanto los elementos en un orden inesperado. El bucle no solo ofrece la posibilidad de escoger el punto de inicio del relato, sino que obliga a ello, y eso permite al guionista salirse de los parámetros narrativos habituales de la serie, convertir a su protagonista momentáneamente en una figura secundaria y elevar al rol principal a un personaje episódico.

Podría decirse que lo que hace Blink es mostrar las consecuencias antes que las causas, si aceptamos que los actos de Sally son consecuencia de los actos del Doctor. Pero esta sería una aproximación muy reduccionista e inexacta, la que los actos del Doctor son, a su vez, consecuencia de los de Sally. El espectador solo tiende a interpretar lo primero por la fuerza de la costumbre: el punto de vista de Doctor Who es el Doctor, y es solo respecto a eso que Blink se convierte en una anomalía. En la obra de Steven Moffat, el desconcierto espectatorial viene dado a menudo por la suma de la circularidad temporal y de la libre reordenación de los sucesos en el relato, lo que maximiza la sorpresa cuando los elementos empiezan a desvelar el modo en que están conectados.

Quizá el mejor y más efectivo uso de esta reordenación sea la propia conversación diferida entre Sally y el vídeo del Doctor. Al separar las dos mitades de dicha conversación, se crea la ilusión de un rompecabezas. Lo primero que ve el espectador es un vídeo con respuestas, sin preguntas, como quien escucha solo un extremo de una conversación telefónica. ¿Qué es $y$, sobre todo, qué falta? Cuando Sally descubre que debe formular las preguntas, el público contempla al fin un diálogo completo, solventando así la incógnita y fundiendo dos planos temporales (imagen grabada e interlocutora actual) en un único presente, que a efectos prácticos funciona como una conversación viva y simultánea entre Sally y el Doctor.

Pero también vale la pena señalar la habilidad para exponer un relato tan estructuralmente complejo como el de Blink de forma transparente y fácilmente comprensible por el espectador. Moffat y la directora Hettie MacDonald se apoyan en mecanismos tradicionales para plasmar una estructura atípica, y en ciertas convenciones de género (concretamente, del terror) para provocar una sensación de familiaridad a pesar del extravagante desarrollo de los acontecimientos. La escena inicial, por ejemplo, transita desde un plano inicial deudor de Ciudadano Kane (Citizen Kane; Orson Welles, 1941), con la fantasmal imagen de la verja que rodea un viejo caserón, hasta la habitual iconografía de 'casa abandonada', mientras Sally explora las estancias del lugar. El elemento de extrañeza son las pintadas que la joven descubre al arrancar el papel de las paredes: mensajes que se dirigen a ella y la advierten del peligro. Aquí la manipulación temporal es más sutil, puesto que aún no ha entrado en juego la figura del viajero del tiempo, y no se han expuesto aún los parámetros en los que se moverá el relato. Sin embargo, lo que está sucediendo es (por más que el espectador aún siga a oscuras al respecto) un primer ejemplo de paradoja circular que, además, permite simultanear dos momentos distintos de forma similar a lo que ocurrirá después con el vídeo del Doctor. Porque, a medida que Sally va retirando el papel de la pared, el mensaje va quedando al descubierto no de golpe, sino en el momento adecuado, como si esa pintada realizada décadas atrás estuviese hablándole a ella en ese preciso instante. Así, tras un genérico "Cuidado", la protagonista descubre las palabras, ya más específicas, "con el ángel lloroso", y un intrigante "y agáchate". Hasta ahí todo es inquietante, pero verosímil dentro de los códigos del cine de terror; el tropo de la inscripción oculta en las paredes de una casa remite directamente a ejemplos como Rojo oscuro, de Dario Argento (Profondo Rosso, 1975). Pero a continuación, Sally revela dos mensajes más: el primero, "Sally Sparrow", convierte la pintada en un vocativo con destinatario claro: ella. Y, por último, un "¡agáchate ya!" hace que la protagonista obedezca la orden justo en el momento en que una piedra se estrella contra la pared por encima de su cabeza. La inscripción (hecha por el Doctor de 1969) salva la vida a Sally (causa-consecuencia), pero a la vez Sally dará al Doctor la información y el motivo para hacer la pintada (consecuencia-causa).

Respecto al uso de mecanismos narrativos convencionales, valga como muestra una temprana secuencia del episodio. Tras la secuencia inicial, Sally regresa al viejo caserón, esta vez con su amiga Kathy. Al separarse momentáneamente, esta última se encontrará con un ángel lloroso, que la enviará al año 1920. En ese mismo instante, un individuo misterioso llega a la casa ruinosa con una carta para Sally. Una carta de Kathy, contándole lo ocurrido, y asegurándole que ha tenido una vida plena $y$ feliz en el pasado ${ }^{5}$. La voz over de Kathy (recurso cinematográfico frecuente en las escenas epistolares) enlaza las imágenes alternas de Sally leyendo y de la propia Kathy, recién aparecida en 1920, conociendo al muchacho con el que se casará. Esto, en sí, no tendría mayor trascendencia si no fuera por algo que fácilmente podría pasar desapercibido: la escena 
pone de manifiesto una nueva forma en que los viajes en el tiempo desafían la terminología habitual de la narración audiovisual. $Y$ es que el analista se sentirá tentado de catalogar las imágenes de Kathy en 1920 como un flashback (o analepsis), y sin duda así es si nos atenemos al 'tiempo externo' del relato. Pero si el punto de referencia es el 'tiempo interno' de Kathy, su escena se situaría en un riguroso presente, y son los planos de Sally leyendo los que se convertirían en un flashforward o prolepsis. $Y$ según el tiempo interno de Sally (que, como se ha señalado antes, es el que determina la focalización del episodio), las imágenes de Kathy podrían ser ambas cosas a la vez.

\section{Under the Lake / Before the Flood}

La historia que narra el díptico formado por los episodios Under the Lake y Before the Flood se articula de forma muy distinta a lo visto en Blink. En primer lugar, por la propia forma que adopta la temporada a la que pertenece: si las demás temporadas de la serie moderna se componen sobre todo de entregas autoconclusivas ( $y$, solo ocasionalmente, algún capítulo doble), esta novena tanda de Doctor Who 2005 desecha casi por completo los relatos autoconclusivos para desplegar sus 12 episodios en cinco historias de dos entregas cada una, y tan solo dos episodios individuales. Por tanto, el showrunner Steven Moffat y el guionista Toby Whithouse aprovechan este desdoblamiento para jugar con la estructura de la paradoja.

Así, el primer episodio, Under the Lake, muestra exclusivamente los eventos de su tiempo 0 narrativo, en el año 2119. El Doctor (interpretado en esta temporada por Peter Capaldi) y su acompañante Clara (Jenna Coleman) llegan a una base subacuática situada junto a un viejo pueblo escocés inundado tiempo atrás. Alli se encuentran con una nave que contiene en su interior una inscripción indescifrable. Los soldados a cargo de la base están muriendo en circunstancias extrañas, y reapareciendo en forma de espectros que murmuran cuatro palabras sin cesar. El Doctor descubre que tanto la inscripción como esas palabras son coordenadas que apuntan a un lugar específico del pueblo sumergido, y encuentran allí un sarcófago cerrado. Para descubrir el significado de todo ello, el Doctor decide regresar atrás en el tiempo, a un punto anterior a la inundación del pueblo, con dos de los tripulantes de la base, mientras Clara permanece en el presente con el resto de la tripulación. Poco después de la partida del Doctor, Clara se encuentra con un nuevo fantasma: el del propio Doctor. A diferencia de los demás, este nuevo espectro murmura un mensaje distinto: los nombres de todos los implicados en la historia, comenzando por los fallecidos, y por tanto indicando el orden en el que el resto va a morir.

Este primer episodio acaba, pues, con un cliffhanger que no solo deja en suspenso la resolución del conflicto, sino que también pone sobre la mesa un peligro nuevo: la aparente muerte del protagonista en algún momento de su viaje al pasado. Sin embargo, Under the Lake se ha limitado a mostrar los acontecimientos de 2119, por lo que el análisis temporal del relato sugeriría que este es el presente narrativo del mismo. Como se verá más adelante, esta afirmación sería incorrecta, o cuando menos incompleta.

Before the Flood retoma los acontecimientos tras el cliffhanger y abandona la linealidad para mostrar el viaje al pasado del Doctor. Este se encontrará cara a cara con el Rey Pescador, el alienígena responsable de la creación de los fantasmas: en realidad, estos son solo recreaciones electromagnéticas de los fallecidos, creadas para repetir y, por tanto, amplificar la señal con las coordenadas que señalan a ese punto concreto de la Tierra, que debe servir como lugar de inicio de una invasión a gran escala. El Doctor se comunica telefónicamente con Clara, que permanece en el siglo XXII, y esta le habla de la aparición del Doctor fantasma y la lista de nombres. Al conocer ese listado, y ante lo que parece la inminente muerte de Clara, el Doctor se decide a acabar con el alienígena, para lo cual provoca la explosión de la presa y la inundación del pueblo, creando así el primer gran bucle temporal del episodio: en 2119 los protagonistas llegan a la base bajo el agua, pero son los sucesos que allí ocurren los que empujan al Doctor a regresar a 1980 y provocar la inundación, que a su vez es condición necesaria para la creación de la base submarina...

El segundo bucle es más sutil, y tiene que ver con el listado de nombres: finalmente, el Doctor fantasma se desvela como un holograma, una artimaña del protagonista en el futuro para transmitir esa información a su yo del pasado e impulsarle así a actuar. Al explicárselo a Clara, esta le felicita por su astucia. La respuesta del Doctor pone de manifiesto la paradoja circular:

Doctor: "Programé a mi fantasma para decir esas palabras porque eso es lo que había dicho mi fantasma. Y la única razón por la que creé mi fantasma holográfico es porque lo vi aquí. Hice retroingeniería con la narrativa."

Clara: "Eso es muy inteligente."

Doctor: "No lo entiendes. ¿Cuándo tuve esa idea por primera vez, Clara?"

Clara: "Debió de ser... guau..."

Doctor: "Exacto: ¿Quién compuso la Quinta Sinfonía de Beethoven?"

\section{(Doctor Who: Before the Flood)}

De nuevo, como en Blink o en el ejemplo con el que se abría Under the Lake, en este sistema circular no existe un punto de origen de las ideas. No hay una génesis, un momento concreto de alumbramiento y, por extensión, un responsable de las mismas. La causalidad es un bucle cerrado de estructura $A \rightarrow B \rightarrow$ 
A, desafiando así la construcción clásica. Por supuesto, la historia que se cuenta en estos dos capítulos tiene un detonante como tal, escogido así por el guionista (el Doctor y Clara llegan a la base y se encuentran con el misterio), pero a diferencia de lo que ocurre en una narración lineal, una sencilla reordenación de los elementos del relato permitiría cambiar el detonante sin modificar en nada los sucesos de su trama. En una construcción no circular, el cambio de detonante implicaría necesariamente un cambio en los hechos que lo rodean.

En este segundo episodio la temporalidad se desdobla. Por un lado, se presenta el viaje del Doctor al pasado (1980), pero por otro, la narración opta por simultanear estos hechos con los que se producen en 2119 tras la partida del protagonista (y la aparición de su fantasma). Parece, a primera vista, una estructura familiar, no muy distinta de la que despliega Francis Ford Coppola en El Padrino: Parte II (The Godfather Part II, 1974), cuando relata en paralelo la juventud de Vito Corleone (Robert de Niro) entre 1901 y 1925 y la peripecia de su hijo Michael en 1958-59 (Al Pacino). Pero, si nos atenemos al tipo de montaje, surge una dificultad en su clasificación. Al fin y al cabo, lo mostrado en El Padrino: Parte /I es un ejemplo de montaje paralelo, es decir, aquel que "muestra de forma sucesiva, alternando fragmentos, dos o más acciones o situaciones que no se desarrollan simultáneamente en el tiempo de la historia" (Canet y Prósper 2009, 401). $\mathrm{Y}$ es indudable que la historia de Vito y la de Michael no se desarrollan de manera simultánea. Pero los acontecimientos en Before the Flood, a pesar de estar separados por 139 años de Historia, están sucediendo simultáneamente para los personajes del futuro y del pasado. Así lo muestran las diferentes escenas en que el Doctor, desde 1980, habla por teléfono con Clara, que permanece en 2119. Se trataría, pues, de un montaje alterno, aquel en el que:

acontecimientos que suceden simultáneamente en la diégesis en espacios distintos son mostrados de forma sucesiva, normalmente alternando distintas partes de cada uno de ellos

(Canet y Prósper 2009, 402-403).

Más concretamente, si se tiene en cuenta el desenlace del episodio, donde el Doctor y Clara se reúnen en 2119, de montaje convergente ("acontecimientos simultáneos que acaban confluyendo en un mismo espacio") que "es una modalidad del montaje alterno" (Canet y Prósper 2009, 403). Ahora bien, si se reorganizaran las secuencias de ambos episodios según la cronología externa, mostrando primero todo lo que acontece en 1980 y después las escenas correspondientes a 2119, ¿se sentiría tentado el analista de considerar que ambas partes "suceden simultáneamente en la diégesis", condición sine qua non para considerar que el episodio, en su forma real, está estructurado en un montaje alterno? ¿O se consideraría que las acciones "no se desarrollan simultáneamente en el tiempo de la historia", y por tanto sería, como en el film de Coppola, un montaje paralelo? En sentido estricto, se trataría de ambos a la vez (con dos presentes narrativos distintos que son, a su vez, diegéticamente simultáneos) por más que sobre el papel (y siguiendo las definciones de Canet y Prósper), estos sean modelos incompatibles entre sí.

\section{Conclusión}

Lo que pone de manifiesto el análisis de estos ejemplos es la inadecuación de las jerarquías y terminologías clásicas al tratar con relatos sobre viajes en el tiempo, particularmente aquellos que incluyan construcciones temporales paradójicas. El desplazamiento en el tiempo de una o varias de las figuras en juego acaba por poner en jaque las categorizaciones estándar de la articulación del tiempo filmico (flashback, flashforward, montaje paralelo o alterno...), así como la noción de detonante y las implicaciones causales. En las narraciones de este tipo, dicha terminología solo será útil para el análisis si, por un lado, se emplea con la suficiente flexibilidad (permitiendo, por ejemplo, la coexistencia de montaje paralelo y alterno en una misma pieza y de manera simultánea) y, por otro, si viene acompañada de una rigurosa identificación del punto de vista y la focalización narrativa. En estos casos se hace necesario introducir una terminología nueva, o al menos complementaria a la anterior.

En esta línea, las nociones de tiempo externo y tiempo personal aportadas por Lewis desde el ámbito de la filosofía (Lewis 1976, 146) pueden y deben funcionar en el análisis narrativo como modificadores que permitan explicar con mayor precisión la articulación temporal de la obra. De este modo, una distorsión de orden que, en tiempo externo, aparezca como flashback, en tiempo personal del viajero puede ser una sencilla progresión lineal. La identificación de la focalización narrativa (interna fija, interna múltiple, externa o relato no focalizado) será, en última instancia, lo que determinará cuál de las dos opciones es la que opera en cada situación específica.

\section{Notas}

\footnotetext{
${ }^{1}$ La numeración oficial de las temporadas de la serie separa esta en dos grandes etapas: para mantener la claridad en la medida de lo posible, nos referiremos a estas como dos series distintas, denominando a la etapa clásica (temporadas 1 a 26) como Doctor Who 1963, y a la moderna (temporadas 1 a 12) como Doctor Who 2005.

${ }^{2}$ En la etapa clásica, los episodios, de alrededor de 25 minutos de duración, se agrupaban en 'seriales', conjuntos de varios capítulos (generalmente entre 2 y 6) que, bajo un título común, narraban una aventura autoconclusiva del Doctor y sus acompañantes. De este modo, por ejemplo, la primera temporada consta de 42 episodios repartidos en 8 seriales.

${ }^{3}$ En un momento del episodio, el Doctor los describirá como "Ios únicos psicópatas del universo que matan amablemente. Sin líos, sin problemas, simplemente te mandan al pasado y te dejan vivir hasta la muerte; el resto de tu vida consumida y desaparecida en un abrir y cerrar de ojos".
} 
${ }^{4}$ Una de las frases del Doctor en la grabación resume el quebradero de cabeza con un sencillo giro gramatical. Cuando Sally le pregunta de dónde sacó la información, él responde: "I got it in the future" (la obtuve en el futuro), conjugando así el futuro con un pretérito perfecto simple.

${ }^{5}$ Se trata, aunque no nos detendremos en ella, de otra paradoja circular de alcance más pequeño: la llegada del mensajero que lleva la carta distrae a Sally un instante, permitiendo al ángel lloroso alcanzar a Kathy. Por tanto la carta es a la vez consecuencia y causante de que esta acabe desplazada al pasado.

\section{Bibliografía}

Aristóteles en García Yebra, Valentín (ed.), 2010. Poética de Aristóteles. Traducido del griego por Valentín García Yebra. Gredos.

Aumont, Jacques y Marie, Michel, 2009. Análisis del film. Traducido del francés por Carlos Losilla. Paidós.

Bordwell, David y Thompson, Kristin, 1995. El arte cinematográfico. Traducido del inglés por Yolanda Fontal Rueda. Paidós.

Canet, Fernando y Prósper, Josep, 2009. Narrativa audiovisual. Estrategias y recursos, Síntesis.

Deleuze, Gilles y Guattari, Félix, 2004. Mil mesetas. Capitalismo y esquizofrenia. Traducido del francés por José Vázquez Pérez con la colaboración de Umbelina Larraceleta. Pre-textos.

Hills, Matt, 2010. Triumph of a Time Lord: Regenerating Doctor Who in the Twenty-First Century, I. B. Tauris.

Lewis, David, 1976. "The Paradoxes of Time Travel”, en American Philosophical Quarterly, vol. 13, núm. 2.

Sánchez-Escalonilla, Antonio, 2001. Estrategias de guión cinematográfico, Ariel.

Steele, Sam, 2008. "Deleuze and the Doctor: Rhizomorphic Time Travel in Doctor Who", en Lux. Undergraduate Journal of Literature and Culture, núm. 2.

Warf, Barney, 2002. "The Way it Wasn't. Alternative Histories, Contingent Geographies" en Kitchin, Rob y Kneale, James, Lost in Space: Geographies in Science Fiction. Bloomsbury.

\section{Filmografía}

Doctor Who. 1963-2021. Reino Unido: BBC

- Blink. 2007. Dirigido por Hettie McDonald.

- Under the Lake. 2015. Dirigido por Daniel O'Hara

- Before the Flood. 2015. Dirigido por Daniel O'Hara

The Godfather Part II. 1974. Dirigida por Francis Ford Coppola. EE UU.

Profondo Rosso. 1995. Dirigida por Dario Argento. Italia. Pulp Fiction. 1994. Dirigida por Quentin Tarantino. EE UU. 